\title{
X-Ray Study of Pressure-Collapsed Fullerite
}

\section{Citation}

Kosowsky, S. D., C.-H. Hsu, Nancy H. Chen, Fred Moshary, Peter S. Pershan, and Isaac F. Silvera. 1993. X-ray study of pressure-collapsed fullerite. Physical Review B 48(11): 8474-8475.

\section{Published Version}

doi:10.1103/PhysRevB.48.8474

\section{Permanent link}

http://nrs.harvard.edu/urn-3:HUL.InstRepos:10357543

\section{Terms of Use}

This article was downloaded from Harvard University's DASH repository, and is made available under the terms and conditions applicable to Other Posted Material, as set forth at http:// nrs.harvard.edu/urn-3:HUL.InstRepos:dash.current.terms-of-use\#LAA

\section{Share Your Story}

The Harvard community has made this article openly available.

Please share how this access benefits you. Submit a story.

\section{Accessibility}




\title{
X-ray study of pressure-collapsed fullerite
}

\author{
S. D. Kosowsky, C.-H. Hsu, Nancy H. Chen, Fred Moshary, P. S. Pershan, and Isaac F. Silvera \\ Division of Applied Sciences and Physics Department, Harvard University, Cambridge, Massachusetts 02138
}

(Received 11 February 1993)

\begin{abstract}
$\mathrm{X}$-ray-diffraction studies are described for a new phase of carbon called collapsed fullerite (CF) that was produced by application of high pressure to fullerite $\left(\mathrm{C}_{60}\right)$. At $\sim 20 \mathrm{GPa}$ there is an irreversible transition to a phase that has neither the (111) Bragg peak of diamond nor any of the Bragg peaks associated with the fcc phase of $\mathrm{C}_{60}$. The spectrum of $\mathrm{CF}$ is flat and featureless in the range of study.
\end{abstract}

In a recent paper, Moshary et al. reported that at $\sim 20$ $\mathrm{GPa}$ fullerite $\left(\mathrm{C}_{60}\right)$ undergoes an irreversible phase transition to a new structure of carbon that was called collapsed fullerite (CF). ${ }^{1}$ CF was found to be very hard, supporting large-pressure gradients, and was optically observed to go from black for pressurized $\mathrm{C}_{60}$ to a semitransparent yellowish color for CF. Although the Raman spectrum of zero-pressure CF showed a broad line centered at about $1550 \mathrm{~cm}^{-1}$ characteristic of an amorphous solid and similar to the Raman spectrum for amorphous carbon ( $a$-carbon), ${ }^{2}$ the optical-absorption spectrum was found to be different from that of $a$-carbon, implying that $\mathrm{CF}$ is a new form of carbon. In this paper we report on $\mathrm{x}$-ray-diffraction studies of zero-pressure CF.

Our sample no. 1 was prepared as the bulk sample reported by Moshary et al. High-purity $\mathrm{C}_{60}$ was heated to $250^{\circ} \mathrm{C}$ and pumped on for a day to remove solvent impurities and possibly oxygen. This was then placed in a T301 stainless-steel gasket and pressurized to $50 \mathrm{GPa}$ in a diamond-anvil cell to transform it into the CF phase. The released sample had an approximate size of $100-\mu \mathrm{m}$ diameter by $40 \mu \mathrm{m}$ thick. Its optical and Raman spectra were measured to confirm that it was CF. A lead shield with a hole for $\mathrm{CF}$ was micromachined and placed over the gasket-CF combination as an $\mathrm{X}$-ray mask. A second sample, no. 2, was made using similar procedures and analyses, but was pressurized in a rhenium gasket.

$\mathrm{X}$-ray-scattering measurements of room-temperature CF were carried out on the wiggler beam line X25 at the National Synchrotron Light Source (NSLS) at Brookhaven National Laboratory, using a monochromatic beam of wavelength $\lambda=1.29 \AA$. X-ray powder patterns were taken in the vertical plane by $\theta-2 \theta$ scans.

Aside from the parasitic Bragg peaks from the lead shield and stainless-steel gasket of sample no. 1, and the rhenium gasket for sample no. 2, no sharp structure was observed in the powder-diffraction spectra of either $\mathrm{CF}$ : for samples nos. 1 and $2, Q_{\max }$ was 4.5 and $5.8 \AA^{-1}$, respectively. The wave-vector region near the diamond (111) peak for sample no. 1 is depicted in Fig. 1(a) by the filled squares. The results from similar scans through almost identical gasket-shield assemblies which were filled with uncompressed $\mathrm{C}_{60}$ fullerite (open squares) and with $1-2-\mu \mathrm{m}$ sized powdered natural diamond grit (solid line) are also displayed in Fig. 1(a). The very intense peak at $Q=3.05 \AA^{-1}$ in the diamond sample, due to the (111) reflection from diamond, is not observed in any other samples. This indicates no measurable residue of the diamond (111) in either the $\mathrm{CF}$ or the $\mathrm{C}_{60}$ data, from which we conclude that the CF sample contains $\lesssim 0.1 \%$ of diamond. The broader peaks at 3.02 and $3.09 \AA^{-1}$ that appear with different intensities in both the $C F$ and $C_{60}$ data, are identified as the stainless-steel peaks by comparing the above spectra with powder-diffraction data (triangles, taken on a different diffractometer and arbitrarily

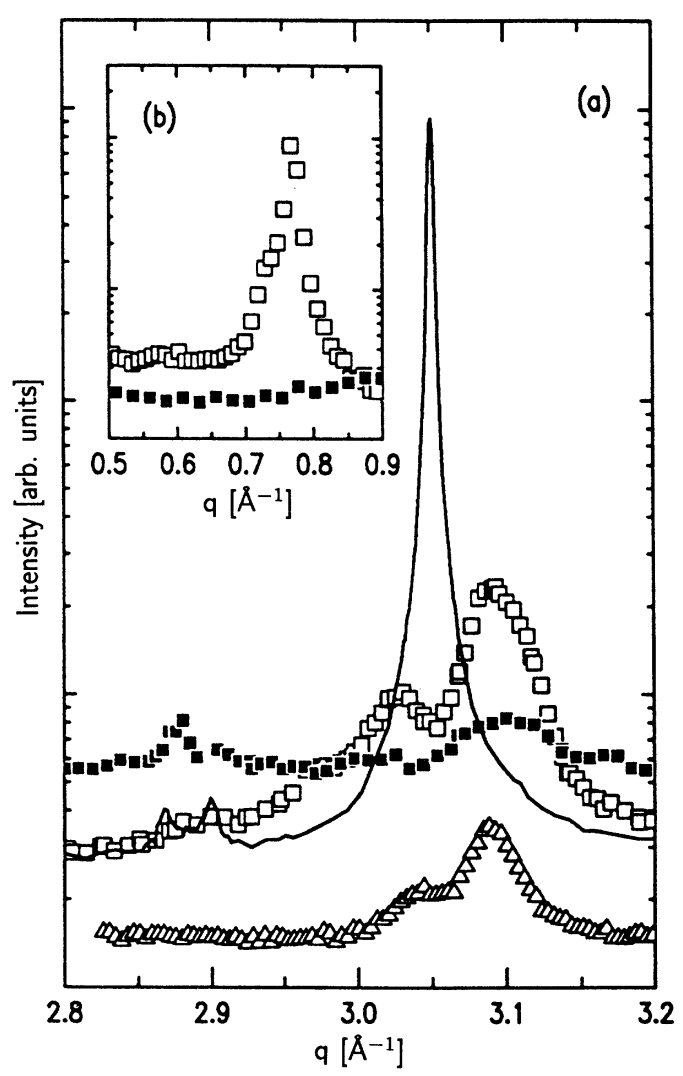

FIG. 1. (a) X-ray scattering data of the region near the diamond (111) peak: diamond (- ); $\mathrm{C}_{60}(\square)$; $\mathrm{CF}$ ( $\square$ ); and scattering from stainless steel $(\triangle$, offset for clarity) that confirms the identity of the corresponding peaks in the other data sets. (b) Inset enlarged views near the $C_{60}(111)$ peak. Same symbols as in (a). 
scaled) for a $0.25-\mathrm{mm}$-thick piece of stainless steel of the same stock from which the gaskets were fabricated. Both the positions and relative intensities of the stainless-steel peaks are in good agreement with the peaks in the $\mathrm{C}_{60}$ data; their absence in the diamond data, as well as their smaller amplitude in the CF data, is probably due to variations in the shielding by the micromachined $\mathrm{Pb}$ shield.

Figure 1(b) contains a superposition of the data from $\mathrm{CF}$ sample no. 1 , and from $\mathrm{C}_{68}$ in the region surrounding the $\mathrm{C}_{60}(111)$ peak, $Q \cong 0.77 \AA^{-1}$. The absence of any measurable trace of the $0.77-\AA^{-1}$ peak in the CF data demonstrates that the $\mathrm{C}_{60}$ content of the CF sample is $\lesssim 1 \%$. Aside from the parasitic peaks due to the shieldgasket assembly, no feature associated with the CF sample can be identified in the range of $Q$ values covered by our measurements $\left(Q \leq 4.5 \AA^{-1}\right)$. Similarly, the only sharp peaks observed in the X-ray spectra of sample no. 2 are the Bragg peaks associated with the Re gasket. Otherwise, a flat featureless spectrum within the range $0 \leq Q \leq 5.8 \AA^{-1}$ was observed for the CF. The absence of any peaks at $\sim 3 \AA^{-1}$, characteristic of the structures with near-neighbor in-plane trigonal bonding similar to that of crystalline graphite and $a$-carbon, ${ }^{3-5}$ indicates that our CF sample has a structure different from that of crystalline graphite and $a$-carbon.

Recent high-pressure studies on fullerite, reported by Núñez-Regueiro and co-workers, showed that their pres- sure transformed $\mathrm{C}_{60}$ samples consisted of tiny crystallites of diamond embedded in an amorphous matrix. ${ }^{6,7}$ The Raman spectrum of their sample shows, in addition to the sharp diamond peak, a broad peak centered at $1450 \mathrm{~cm}^{-1}$, which is different from that observed by Moshary et al. The work of Núñez-Regueiro and coworkers differs from other static pressurization studies, as large samples (of order $1 \mathrm{~mm}^{3}$ ) were compressed using sintered diamond anvils and produced substantially larger samples. The difference in sample preparation may lead to a different structure in their samples.

In summary, $x$-ray powder-diffraction results show no traces of diamond, graphite, or residual $\mathrm{C}_{60}$ in our $\mathrm{CF}$ samples: $\mathrm{CF}$ appears to have a flat featureless spectrum in the region of study, i.e., $Q \leq 6 \AA^{-1}$.

We thank Lonny E. Berman for his assistance in the setup on X-25 and T. A. Rabedeau and S. Lee for helpful discussions. We are grateful to Don Bethune and colleagues for the fullerite from which the CF was prepared. This research was supported in part by the National Science Foundation grant to Harvard MRL, NSF, DMR91-13782. Research carried out at the NSLS, Brookhaven National Laboratory, was supported by the Department of Energy, Materials Science and Division of Chemical Sciences under Contract No. DE-AC02$76 \mathrm{CH} 00016$.
${ }^{1}$ F. Moshary, N. H. Chen, I. F. Silvera, C. A. Brown, H. C. Dorn, M. S. de Vries, and D. S. Bethune, Phys. Rev. Lett. 69, 466 (1992).

${ }^{2}$ A. Richter, H. J. Scheibe, W. Pompe, K. W. Breziha, and I. Mühling, J. Non-Cryst. Solids 88, 131 (1986).

${ }^{3}$ B. J. Stenhouse and P. J. Grout, J. Non-Cryst. Solids 27, 247 (1978).
${ }^{4}$ D. F. R. Mildner and J. M. Carpenter, J. Non-Cryst. Solids 47, 391 (1982).

${ }^{5}$ F. Li and J. S. Lannin, Phys. Rev. Lett. 65, 1905 (1990).

${ }^{6}$ M. Núñez-Regueiro, P. Monceau, and J. L. Hodeau, Nature 355, 237 (1992).

${ }^{7}$ M. Núñez-Regueiro, P. Monceau, L. Abella, G. Lucazeau, and J.-L. Hodeau (unpublished). 